\title{
Essential oil from Cymbopogon nardus and repellant activity against Aedes aegypti
}

\author{
NI LUH ARPIWI ${ }^{1, \boldsymbol{\varphi}}$, I KETUT MUKSIN ${ }^{1}$, NI LUH KARTINI $^{2}$ \\ ${ }^{1}$ Department of Biology, Faculty of Mathematics and Natural Sciences, Universitas Udayana. Jl. Raya Kampus Unud Jimbaran, Badung 80361, Bali, \\ Indonesia. Tel./fax.: +62-361-701954, `email: arpiwi@unud.ac.id \\ ${ }^{2}$ Department of Agroecotechnology, Faculty of Agriculture, Universitas Udayana. Jl. PB. Sudirman, Denpasar 80232, Bali, Indonesia
}

Manuscript received: 7 June 2020. Revision accepted: 30 July 2020.

\begin{abstract}
Arpiwi NL, Muksin IK, Kartini NL. 2020. Essential oil from Cymbopogon nardus and repellant activity against Aedes aegypti. Biodiversitas 21: 3873-3878. Cymbopogon nardus (L.) Rendle is an aromatic grass from the Poaceae family that produces essential oil mainly in the leaves. The essential oil from $C$. nardus is known as citronella oil has repellent activity. This research aimed to quantify the oil content of $C$. nardus leaves, to analyze the essential oil quality, to analyze the repellent activity of lotion with different concentrations of citronella oil against Aedes aegypti, and to examine the quality of formulated lotions. The oil was extracted from leaves using steam distillation, and the quality was examined according to the Indonesian National Standard. The citronella oil was formulated into a lotion with five concentrations $(0,2,3,4,5 \% \mathrm{w} / \mathrm{w})$. Repellent activity of the lotions against Ae. aegypti was tested using screened cage test method under laboratory conditions. Lotion quality was analyzed for $\mathrm{pH}$, viscosity, homogeneity, and sensorial assessments. The result showed that the oil yield of $C$. nardus leaves was $0.9 \%$ w/w. The color of the oil was pale yellow, specific weight was 0.8819 , the refraction index was 1.464 , total geraniol was $72.71 \%$, citronellal content was $49.14 \%$, and solubility in $80 \%$ alcohol 1:2 was clear. The repellent activity of lotions with citronella oil was concentration-dependent, where a concentration of $5 \%$ gave the highest protection. The quality of formulated lotions met the standard and the lotions were nonirritant.
\end{abstract}

Keywords: Distillation, lotion, oil yield, protection, quality

\section{INTRODUCTION}

Essential oil is lipophilic and volatile at room temperature consisting of a mixture of various organic compounds that generally have a low molecular weight. Essential oils are known as etheric oils and flying oils produced in almost all plant organs, including roots, stems, leaves, fruit, flowers, seeds, and bark (Dhifi et al. 2016). Essential oils are used for various fields, for example, perfumes, cosmetics, medicines, and food preservatives (Perricone et al. 2015). Cymbopogon nardus is a perennial grass from family Poaceae growing in tropical and subtropical regions including Asia, Africa, and America. Essential oils from $C$. nardus are known as citronella oil, with three main active components, namely citronellal, citronellol, and geraniol (Wany et al. 2014).

The essential oil from $C$. nardus is generally extracted from fresh leaves using a steam distillation method. In addition, there is also manual extraction using organic solvents such as methanol, hexane, and petroleum ether called maceration using dried leaf samples (Wany et al. 2014). Distillation is the process of separating between liquid and solid components from two kinds of mixtures based on differences in vapor points. The steam distillation method is the most commonly used for separating essential oils from plant materials. The samples are placed into a chamber then closed tightly, and this chamber is connected to a cooling system to condense steam containing essential oils. Mixture of essential oil with hydrosol drips from the cooling system to form two layers, oil on the top, and hydrosol at the bottom layer (Božović et al. 2015).

One of the biological activities of citronella oil is a repellent activity which is the ability to resist the landing or biting of insects on human or animal skin (Nerio et al. 2010; Ranasinghe et al. 2016; Shivhare et al. 2018; Yadav et al. 2014). Female mosquitos Aedes aegypti is a vector of dengue fever disease that threatens life (Soonwera 2015). One way to prevent dengue fever disease is by protecting from Ae. aegypti mosquito bites using an anti-mosquito lotion. The chemical used in commercial anti-mosquito lotions is $\mathrm{N}$, N-Diethyl-meta-toluamide (DEET), which gives long duration and high protection from mosquito bites. However, some problems associated with long term use of the chemicals, including human and environmental problems (Gheeta and Roy 2014). The absorption of DEET in the skin through systemic vessels can cause skin irritation and central nervous disorders (Miot et al. 2011). For this reason, it is very urgent to find DEET's natural substitute ingredients, one of which is citronella oil. Plantbased mosquito repellent is safe for human, animal, and environmentally friendly (Soonwera 2015). In addition, the use of repellent in the form of lotion does not only protect the skin from insect bites but also moisturizes the skin (Misni et al. 2017). The aims of the present study were to analyze essential oil yield from $C$. nardus and its quality based on National Indonesian Standard, to investigate the repellent activity of formulated lotions against Ae.aegypti, and to measure the quality of formulated lotion for $\mathrm{pH}$, viscosity, homogeneity, and sensorial analysis. 


\section{MATERIALS AND METHODS}

\section{Plant materials}

Leaf samples of Cymbopogon nardus were obtained from Megati Village, Tabanan District, Bali, Indonesia. Samples were taken in the morning from 8.00 to $10.00 \mathrm{am}$ and then shorted for good quality leaves which were fresh and green. Leave samples were wrapped with plastic bags and transported to Plant Physiology Laboratory, Department of Biology, Udayana University, Bali, Indonesia.

\section{Extraction of essential oils}

The extraction of essential oil from C. nardus was performed using steam distillation. Freshly leaf samples (5 $\mathrm{kg}$ ) was placed in a sample tank and then tightly closed by tightening the cover bolts so that there are no leaks. The sample thank was connected by a pipe to a boiler that produces steam, then these were connected to the condenser. The condenser was equipped with a hose for water from entering and exiting, so it cools. The gas stove was ignited under the boiler and this produces steam that extracts essential oil from samples. A mixture of hydrosol and essential oil dripped from the condenser and collected in the separator. Essential oils were separated from hydrosol using a separating funnel. Purification was then carried out by the addition of $\mathrm{Na}_{2} \mathrm{SO}_{4}$ to absorb water then filtered with filter paper. The yield of essential oil yield was calculated by the formula:

$$
\text { Oil yiald }=\frac{\text { waight of the oil }(g)}{\text { weight of sample }(g)} \times 100 \%
$$

\section{Quality analysis of essential oil}

Analysis of quality of essential oil was performed based on the National Indonesian Standard (SNI 06-3953-1995), including color, specific weight, refraction index, total geraniol, citronella, and solubility in alcohol. Specific weight was measured using the pycnometer (Iwaki) and refraction index using a refractometer (Bausch \& Lomb) at $20^{\circ} \mathrm{C}$.

\section{Formulation of lotion with essential oil}

The lotion is an oil-in-water $(\mathrm{O} / \mathrm{W})$ type of emulsion with higher viscosity than a cream. The procedure preparing an $\mathrm{O} / \mathrm{W}$ emulsion is by mixing oil and aqueous phases in separate containers. The oil phase is changed into minute globules, each surrounded by thin films of emulsifiers. This wrapped globules then suspended into aqueous phase to form lotion (Khan et al. 2011). Virgin coconut oil (VCO) was the oil base of the lotion containing mainly lauric acid (Ghani et al. 2018) that can maintain skin moisture (Atmanto 2019). Triethanolamine (TEA) was both emulsifier and $\mathrm{pH}$ adjuster forming oil emulsion in water. A combination of TEA and stearic acid forms a salt triethanolamine stearate that functions as a good emulsifier for an oil-in-water type of emulsion (Rowe et al. 2016). The procedure of making lotion followed a method by Yadav et al. (2014) with modification. The lotion was prepared by heating the oil phase and the aqueous phases in separate containers according to the formula in Table 1. The oil phase consisting of VCO, cetyl alcohol, and stearic acid were heated at $70^{\circ} \mathrm{C}$ on a hot plate using separate beaker glasses. After the ingredients have melted, they were mixed into a new beaker glass while stirring. The aqueous phase consisting of distilled water, triethanolamine, and glycerin were heated at $70^{\circ} \mathrm{C}$ while stirring gently until evenly mixed. The aqueous phase was slowly added to the oil phase while stirring gently to form a homogeneous emulsion. The emulsion was cooled to room temperature, then it was added with methylparaben to obtain oil-in-in water $(\mathrm{O} / \mathrm{W})$ basis lotion. Essential oil from C. nardus was added according to the formula in Table 1. The formula was modified from Priyadarsini et al. (2018) where almond oil was replaced with virgin coconut oil and benzyl alcohol was replaced with methylparaben as a preservative.

\section{Sensorial and quality analysis of the lotions}

All lotion formulas were sensory analyzed for color, odor, and sensitivity while the quality was measured for $\mathrm{pH}$, viscosity, and homogeneity. Measurement of $\mathrm{pH}$, viscosity, and homogeneity was following the method by Indonesian Standard for sunscreen lotion (SNI 16-43991996). The color of the lotions was observed visually, and the odor was smelled and noted.

Table 1. Formulation of lotions with different concentrations of essential oil from Cymbopogon nardus (Modified from Priyadarsini et al. 2018)

\begin{tabular}{|c|c|c|c|c|c|c|}
\hline \multirow{2}{*}{ Ingredient } & \multirow{2}{*}{ Function } & \multicolumn{5}{|c|}{ Formulations (\%w/w) } \\
\hline & & F0 & F1 & F2 & F3 & F4 \\
\hline Virgin Coconut Oil & Oil base & 5 & 5 & 5 & 5 & 5 \\
\hline Cetyl alcohol & Thickener & 2 & 2 & 2 & 2 & 2 \\
\hline Stearic acid & Emulsifier & 3 & 3 & 3 & 3 & 3 \\
\hline Glycerin & Humectant & 3 & 3 & 3 & 3 & 3 \\
\hline Triethanolamine & $\mathrm{pH}$ adjuster and emulsifier & 1.2 & 1.2 & 1.2 & 1.2 & 1.2 \\
\hline Methylparaben & Preservative & 0.1 & 0.1 & 0.1 & 0.1 & 0.1 \\
\hline E.O. from C. nardus & Mosquito repellent & 0 & 2 & 3 & 4 & 5 \\
\hline Distilled water add & Diluent & 100 & 100 & 100 & 100 & 100 \\
\hline
\end{tabular}




\section{Sensitivity test}

The sensitivity test was performed by applying the lotion to 10 males and 10 females human volunteers aged from 25 to 45 years old with bodyweight from $50-75 \mathrm{~kg}$. Each volunteer was given five lotions (F0, F1, F2, F3, and F4) that were applied each day for five days following the method by Widawati and Riandi (2015) with modification. Approximately 1 gram of lotion was topically applied to the forearm and behind the ear. The observation was conducted 6 hours post application for any indications of irritation, including skin rash, itch, and swollen.

\section{pH measurement}

Measurement of $\mathrm{pH}$ was conducted using a $\mathrm{pH}$ meter (Mettler Toledo) to $10 \%$ of the solution. The $\mathrm{pH}$ meter was calibrated and then the probe was dipped in the test solution until constant reading. Reading was taken in triplicates.

\section{Viscosity}

The viscosity of lotions was measured by using Brookfield Viscometer DV-E by immersing the spindle into the lotion. Measurement was conducted three times using spindle number 04 at the speed of $100 \mathrm{rpm}$ at room temperature.

\section{Homogeneity}

The homogeneity test was performed by spreading the lotion into the surface of an object-glass and then observed. If there were no solid or coarse grains, the lotion is homogenous.

\section{Rearing Aedes aegypti mosquito}

Colonies of Ae. aegypti were reared in the cages $(30 \mathrm{x}$ $30 \times 40 \mathrm{~cm}^{3}$ ) at a controlled temperature of $20^{\circ} \mathrm{C}$ in the Pathology Laboratory, Faculty of Medical, Udayana University, Bali, Indonesia. The life cycle of the mosquito was 10-12 days. The eggs were dipped in well water for 45 days. These developed into a pupa within 5-7days and hatched into adult mosquitos within a week. Adult mosquitos were fed with guinea pig once a week

\section{Repellency testing}

Repellency testing was performed using a screened cage test method under laboratory conditions (Phasomkusolsil and Soonwera 2010). Twenty-five starves female Ae. aegypti mosquitoes were placed in a cage measuring $20 \times 20 \times 20 \mathrm{~cm}^{3}$. The cage was wrapped in a cloth so that the activity of mosquitoes was easily observed. Human hands were used as a treatment; the right hand was as a control (without lotion) and the left was as a treatment. Both hands were washed with unscented soap and rinsed with running tapped water and dried using a towel before the experiment. Base lotion and commercial insect repellent lotion containing DEET were used as negative and positive control, respectively. Lotion $(1 \mathrm{~mL})$ was applied to the left hand by using a brush. The test was preceded by exposing the right hand, then followed by the left hand for 5 minutes. The test was carried out for 6 hours, where each period was 1 hour with 5 minutes of exposure. Observations were made on the number of mosquitoes that perched or bit on the hands. The repellent activity was measured as the protection ability calculated using the formula by Wathoni et al. (2018):

$$
\text { Protection ability }(\%)=\frac{\Sigma(C-T)}{\Sigma C} \times 100
$$

Where, C: mosquito perch on control hand, T: mosquito perch on treated hand

\section{Data analysis}

The yield of essential oil was calculated for the mean and SD using Microsoft Excel. The protection ability of the lotions against Ae. aegypti and quality of formulated lotions were analyzed using One Way ANOVA within SPSS version 24 to see the differences among treatments. If there are any significant differences, it was continued with Post Hoc analysis using Duncan.

\section{RESULTS AND DISCUSSION}

\section{Oil yield and quality of essential oil from $C$. nardus}

The yield of essential oil from C. nardus leaves after steam distillation with five replications was $0.9 \% \mathrm{w} / \mathrm{w}$. The yield of citronella oil in the present study was higher compared to another study using steam distillation, which is $0.43 \%-0.64 \%$ (Weng et al. 2015). Hydro distillation using a Clevenger-type apparatus yields $0.7 \%$ w/w citronella oil (Kamari et al. 2018). Regardless method of extractions, there are other important factors influencing the yield of essential oil in C. nardus, namely developmental stages of the concerned organs and seasonal variation (Figueiredo et al. 2008; Ganjewala and Luthra 2010). In the present study, the leave samples used for extraction were fully developed, and the season during sampling was the dry season.

Table 2. Quality of essential oil from Cymbopogon nardus (citronella oil) compared to National Indonesian Standard

\begin{tabular}{llll}
\hline Test & Unit & Citronella oil & SNI 06-3953-1995 \\
\hline Color & & pale yellow & pale yellow to pale brown \\
Specific weights, $20^{\circ} \mathrm{C} / 20^{\circ} \mathrm{C}$ & & 0.8819 & $0.880-0.922$ \\
Refraction index $\left(\mathrm{nD}_{20}\right)$ & $\%$ & 1.464 & $1.466-1.475$ \\
Total geraniol & $\%$ & 72.71 & min. 85 \\
Citronella & & 19.14 & min. 35 \\
Solubility in alcohol $80 \%$ & & $1: 2$ clear) & $1: 2$ clear \\
\hline
\end{tabular}


The quality of citronella oil was presented in Table 2 . The color of essential oil from $C$. nardus was pale yellow with specific gravity at $20^{\circ} \mathrm{C}$ was 0.8819 . Both color and specific gravity met the requirement of National Indonesian Standard Number 06-3953-1995 for citronellal oil. The refraction index of citronellal oil was 1.464 , which was slightly lower than the standard (1.466-1475). The total geraniol of essential oil from C. nardus was $72.71 \%$, and this was $12.29 \%$ lower than the minimum standard. Citronellal content was $49.14 \%$, and this was higher than the minimum standard. The solubility in alcohol $80 \%$ met the requirement of the standard.

Sensorial analysis of the lotions (Table 3 ) showed that the color ranged from white (F0/basis lotion) to yellowishwhite. The color turns to slightly yellow (yellowish-white) by the addition of citronella oil. The original color of citronella oil was pale yellow (Table 2), and this influenced the color of lotion. Citronella oil also changed the odor of the lotions. All formulated lotions had citronella oil odors, except the base lotion had no odor. According to the sensorial observation toward 20 volunteers, all of the volunteers have no skin rash, itch, and swollen after applying the lotion to the forearm and behind the ear for six hours. This means that the formulated lotions with citronella oil were nonirritant.

\section{Analysis of quality of lotion}

Analysis of quality of the lotions (Table 4) indicated that $\mathrm{pH}$, viscosity, and homogeneity were met the requirement of the Indonesia National Standard 16-4399. 1996. Basis lotion ( $\mathrm{F} 0)$ had the lowest $\mathrm{pH}$, and this is significantly different $(\mathrm{P}<0.05)$ from other formulation. The addition of citronella oil increased the $\mathrm{pH}$, and the range of $\mathrm{pH}$ of lotion was 5.83 (F0) to 7.29 (F4). This $\mathrm{pH}$ value was within the range of skin $\mathrm{pH}$ (Yadav et al. 2014).
The viscosity of the lotions varied from $2433.00 \pm 22.06$ $\mathrm{cP}$ to $2969.67 \pm 61.70 \mathrm{cP}$ and these were within the standard range. Basis lotion (F0) had the highest viscosity which was $2967.67 \pm 61.70 \mathrm{cP}$ and adding citronella oil decreased viscosity significantly $(\mathrm{P}<0.05)$. Viscosity is a measure of the thickness of the lotion, which indicates the easiness of the lotion to be applied to the skin (Yadav et al. 2014). The appearance of all formulated lotions was homogenous without any solid or coarse grains. This means that the emulsion had mix homogenously and no separation of ingredients so that the oil phase mix eventually with the aqueous phase. The lotion is an example of emulsion, which is a mixture of immiscible liquids where one is dispersed in the others, and these are stabilized by emulsifiers. Emulsifier works by reducing the surface tension of the two phases and creates a thin film around the droplets of the dispersed phase (Khan et al. 2011). There are oil-in-water and water-in-oil types of emulsions (Zhu et al. 2019). In the present study, lotions with citronella oil was an oil-in-water $(\mathrm{O} / \mathrm{W})$ type of emulsion where the oil droplets dispersed finely in the aqueous phase. The lotion is easily spread over the skin surface, less greasy, and easily washable with water (Mohiuddin 2019).

\section{Repellent activity}

Repellent activity of lotions was measured as protection ability presented in figure 1 . As can be seen from figure 1 that all treatments had significantly different $(\mathrm{P}<0.05)$ protection ability compared to control + and control during the six hours of the experiment. Basis lotion (control -) gave the lowest protection ability during the course of the experiment. It as $47.03 \%$ at the beginning and decreased to 11.01 at the end of the experiment. The protection ability of commercial anti-mosquito lotion containing DEET (control+) was $94.26 \%$ at $0 \mathrm{~h}$, and this decreased gradually over time, and it was $32.7 \%$ at $6 \mathrm{~h}$.

Table 3. Sensorial analysis of the formulated lotions

\begin{tabular}{|c|c|c|c|c|c|}
\hline \multirow{2}{*}{ Lotion formula } & \multirow{2}{*}{ Color } & \multirow{2}{*}{ Odor } & \multicolumn{3}{|c|}{ Sensitivity } \\
\hline & & & Skin rash & Itch & Swollen \\
\hline F0 & White & No odor & Nil & Nil & Nil \\
\hline F1 & White & Very mild & Nil & Nil & Nil \\
\hline $\mathrm{F} 2$ & Yellowish white & Mild citronella oil & Nil & Nil & Nil \\
\hline F3 & Yellowish white & Mild citronella oil & Nil & Nil & Nil \\
\hline $\mathrm{F} 4$ & Yellowish white & Mild citronella oil & $\mathrm{Nil}$ & Nil & Nil \\
\hline
\end{tabular}

Note: F0: basis lotion, F1: lotion with $2 \%$ citronella oil, F2: lotion with 3\% citronella oil, F3: lotion with 4\% citronella oil, F4: lotion with $5 \%$ citronella oil

Table 4. Quality of formulated lotions compared to Indonesian National Standard (SNI 16-4399-1996)

\begin{tabular}{llccccc}
\hline \multirow{2}{*}{ Characteristic } & \multirow{2}{*}{ SNI 16- 4399-1996 } & \multicolumn{4}{c}{ Lotion formulation } \\
\cline { 3 - 6 } & & F0 & F1 & F2 & F3 & F4 \\
\hline pH & $4.5-8.0$ & $5.83 \pm 0.86^{\mathrm{a}}$ & $6.53 \pm 0.80^{\mathrm{b}}$ & $6.78 \pm 0.30^{\mathrm{b}}$ & $7.05 \pm 0.67^{\mathrm{d}}$ & $7.29 \pm 0.52^{\mathrm{e}}$ \\
Viscosity (cP) & $2000-5000$ & $2967.67 \pm 61.7^{\mathrm{e}}$ & $2745.33 \pm 6.43^{\mathrm{d}}$ & $2668.00 \pm 15.72^{\mathrm{c}}$ & $2549.33 \pm 14.64^{\mathrm{b}}$ & $2433.00 \pm 22.06^{\mathrm{a}}$ \\
Homogeneity & Homogenous & Homogenous & Homogenous & Homogenous & Homogenous & Homogenous \\
\hline
\end{tabular}

Note: Values are means of three measurements \pm standard deviation, followed by different letters are significantly different $(\mathrm{P}<0.05)$. F0: basis lotion, F1: lotion with $2 \%$ citronella oil, F2: lotion with $3 \%$ citronella oil, F3: lotion with $4 \%$ citronella oil, F4: lotion with $5 \%$ citronella oil 


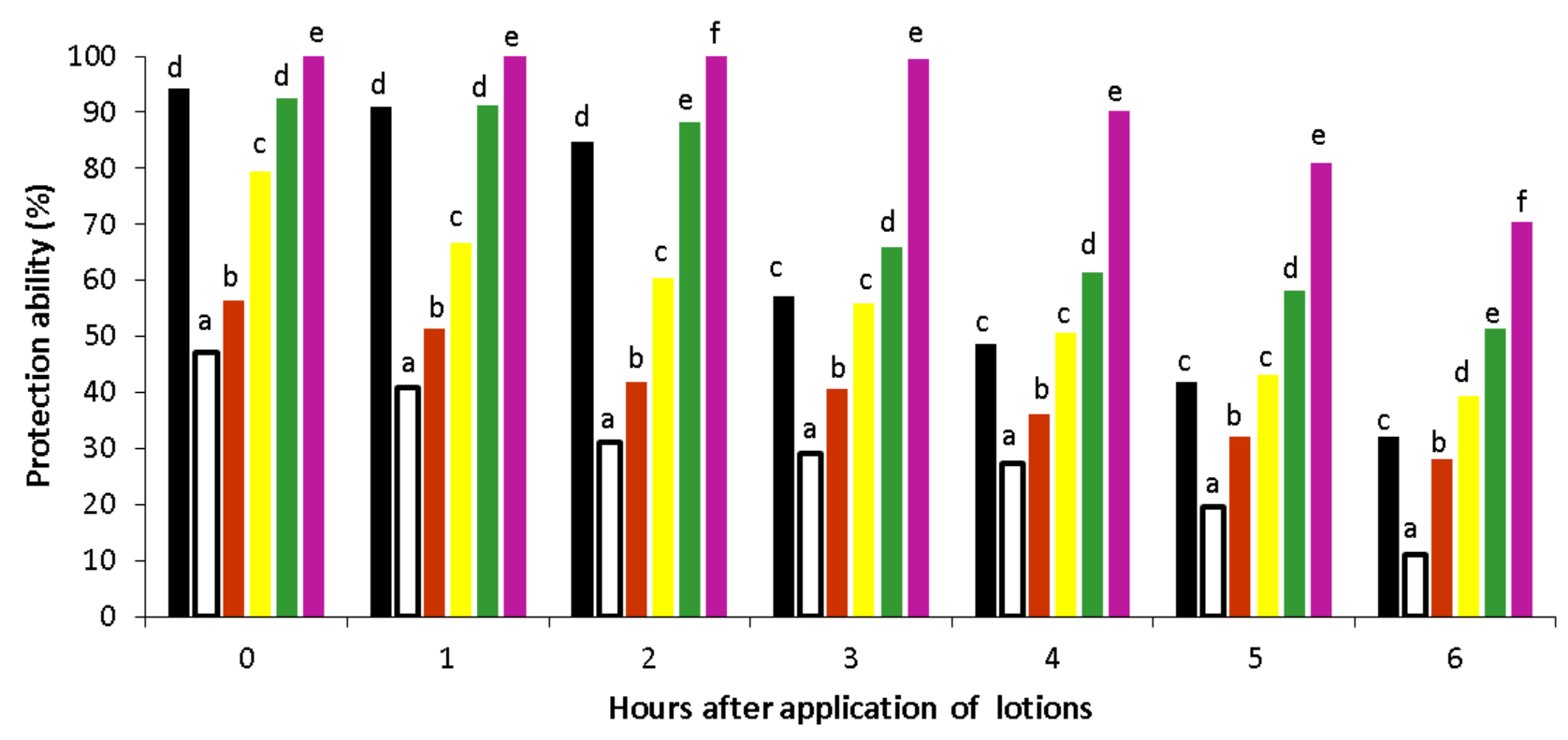

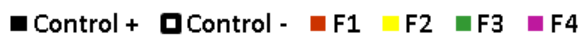

Figure 1. Protection ability (\%) of formulated lotions against Ae. aegypti at different hours after application to the hands. Control +: commercial antimosquito lotion X, Control -: basis lotion, F1: lotion with 2\% citronella oil, F2: lotion with 3\% citronella oil, F3: lotion with $4 \%$ citronella oil, F4: lotion with $5 \%$ citronella oil. Values were means of 4 replications. Different letters above each bar were significantly different $(\mathrm{P}<0.05)$ at each time after application

Lotions with citronella oil gave higher protection than commercial lotion and basis lotion. The protection ability increased as the concentration of citronella oil increased. This is in accordance with other studies that the protection is concentration response-dependent (Karunamoorthi et al. 2014; Solomon et al. 2012). Lotion with $2 \%$ of citronella oil had $56.48 \%$ protection ability at $0 \mathrm{~h}$, and it decreased slightly to $51.34 \%$ at $2 \mathrm{~h}$ and finally $28.12 \%$ at $6 \mathrm{~h}$. Lotion with $3 \%$ citronella oil had $79.34 \%$ protection ability at $0 \mathrm{~h}$, and it decreased gradually to $39.49 \%$ at $6 \mathrm{~h}$. Lotion with $3 \%$ citronella oil gave $92.61 \%$ protection and it decreased to $51.48 \%$ at $6 \mathrm{~h}$. The highest protection ability of $100 \%$ was given by lotion with $5 \%$ citronella oil at 0,1 , and $2 \mathrm{~h}$, respectively. Protection ability then decreased very slightly to $99.49 \%$ at $3 \mathrm{~h}$, to 90.17 at $4 \mathrm{~h}$, to $81.05 \%$ at $5 \mathrm{~h}$, and to $70.36 \%$ at $6 \mathrm{~h}$. Reduction in protection ability overtime of all citronellal lotions tested probably due to the evaporation of the essential oil since the oil is highly volatile at room temperature (Phasomkusolsil and Soonwera 2010). Protection was given after the application of citronella lotion onto the skin, and this provided immediate vapor barrier that deterred mosquito from landing. In the present study, essential oil from $C$. nardus contained monoterpenes, such as geraniol $(72.71 \%)$ and citronellal (49.14\%) (Table 2). According to De Toledo et al. (2016) and Hamzah et al. (2014), the major component of $C$. nardus essential oil is oxygen-containing monoterpenes such as citronellal, citronellol, geranial, geraniol, and citral. These compounds work synergistically as repellents (Nerio et al. 2010).
One possible solution for increasing protection time is by encapsulating the essential oil into a polymer, which increases the duration of repellency significantly. The active ingredients of the essential oil are encapsulated within the wall of polymer to form microcapsules sized 1$100 \mu \mathrm{m}$. Using this technique, the evaporation of active ingredients can be prevented (Misni et al. 2017). Formulation of lotion with citronella oil is also a method of prolonging protection ability and at $5 \%$ citronellal oil gave nearly full protection from Ae. aegypti for 3 hours (180 minutes). In another study, the use of citronella oil alone (without formulation) gives shorter protection which is 115 minutes with $0.8 \%$ biting rate (Phasomkusolsil and Soonwera 2010). It means that the corporation of citronella oil into lotion increased protection time by 65 minutes. However, combining citronellal oil with some other essential oils (Eucalyptus globulus, Murraya Koenigii, C. citratus, Tridex procumbens, and Azadirachta indica) and formulating them into a gel does not improve repellent activity (Shivhare et al. 2018) compared to the present study.

The concentration of citronella oil used in the present study for $100 \%$ protection from Ae. aegypti for 2 hours was $5 \%$, and this was a much lower concentration compared to other studies. For example, Solomon et al. (2012) used $10 \%$ and $20 \%$ of citronella oil formulated in a cream give $90 \%$ and $95 \%$ protection respectively at $0 \mathrm{~h}$ against Anopheles arabiensis. However, at subsequent hours, protection decreases to about $80 \%$ up to 3 hours. Sritabutra and Soonwera (2013) find that $10 \%$ of citronella oil in 
olive oil gives 54.75 minutes of protection from Ae. aegypti while $10 \%$ citronellal oil in coconut oil gives 82.5 minutes protection with a $1 \%$ bite. Indeed formulation of $5 \% \mathrm{w} / \mathrm{w}$ citronella oil into $\mathrm{O} / \mathrm{W}$ lotion in the present study was effective to protect from Ae. aegypti for nearly 3 hours. This low concentration of citronella oil in the lotion and the use of single essential oil in the lotion might more economically beneficial compared to higher concentration and combined oils.

In conclusion, the yield of essential oil from fresh leaves of $C$. nardus extracted using steam distillation was $0.9 \% \mathrm{w} / \mathrm{w}$. The quality of essential oil met the requirement of Indonesian National Standard (SNI 06-3953-1995) for color, specific weight, citronellal content, and solubility in alcohol $80 \%$. However, the refraction index, and total geraniol were slightly lower than the standard. Protection ability of anti-mosquito lotion with citronella essential oil was concentration-dependent, where the concentration of $5 \%$ gave $100 \%$ protection for 2 hours and $99 \%$ up to 4 hours against Ae. aegypti. The formulated lotions were nonirritant.

\section{ACKNOWLEDGEMENTS}

We would like to acknowledge the Ministry of Education and Culture, Republic Indonesia for funding this research through DIPA PNBP 2019, Udayana University, Denpasar, Indonesia with research scheme Hibah Unggulan Udayana.

\section{REFERENCES}

Atmanto D. 2019. Effectiveness of utilizing VCO oil and castor oil on natural creams for dry skin treatment due to environmental factors. J Phys Conf Ser 1402: 022093. DOI:10.1088/17426596/1402/2/022093

Božović M, Navarra A, Garzoli S, Pepi F, Ragno R. 2015. Essential oils extraction: a 24-hour steam distillation systematic methodology. Nat Prod Res. DOI: 10.1080/14786419.2017.1309534.

De Toledo LG, Ramos MADS, Spósito L, et al. 2016. Essential oil of Cymbopogon nardus (L.) Rendle: a strategy to combat fungal infections caused by Candida species. Intl J Mol Sci 17:1252-1267.

Dhifi W, Bellili S, Jazi S, Bahloul N, Wissem Mnif W. 2016. Essentia oils chemical characterization and investigation of some biological activities: a critical review. Medicines 25: 1-16.

Figueiredo AC, Barroso JG, Pedro LG, Johannes JC, Scheffer JJC. 2008 Factors affecting secondary metabolite production in plants: volatile components and essential oils. Flavour Fragrance J 23: 213-226.

Ganjewalaa D, Luthra R. 2010. Essential oil biosynthesis and regulation in the Genus Cymbopogon. Nat Prod Commun 5: 163-172.

Ghani NAA, Channip AA, Hwa PCH, Ja'afar F, Yasin HM, Usman A. 2018. Physicochemical properties, antioxidant capacities, and metal contents of virgin coconut oil produced by wet and dry processes. Food Sci Nutr 6: 1298-1306

Gheeta R, Roy A. 2014. Essential oil repellents-a short review. Intl J Drug Dev Res 6: 20-27.

Hamzah MH, Man HC, Abidin ZZ, Jamaludin H. 2014. Comparison of citronella oil extraction methods from Cymbopogon nardus grass by ohmic-heated hydrodistillation, hydro-distillation, and steam distillation. BioResources 9: 256-272.
Kamari FEL, Taroq A, Atki YE, et al. 2018. Cymbopogon nardus L. essential oil: phytochemical screening and its antibacterial activity against clinical bacteria responsible for nosocomial infections in neonatal intensive care. Intl J Pharm Sci Rev Res 50: 14-17.

Karunamoorthi K, Girmay A, Hayleeyesus SF. 2014. Mosquito repellent activity of essential oil of Ethiopian ethnomedicinal plant against afro-tropical malarial vector Anopheles arabiensis. J King Saud Univ Sci 26: 305-310.

Khan BA, Akhtar N, Khan HMS, et al. 2011. Basics of pharmaceutical emulsions: a review. Afr J Pharm Pharmacol 5: 2715-2725.

Misni N, Nor ZM, Ahmad R. 2017. Repellent effect of microencapsulated essential oil in lotion formulation against mosquito bites. J Vector Borne Dis 54: 44-53.

Mohiuddin AK. 2019. Review article skincare creams: Formulation and use. OSP J Clin Trials 1: 1-22.

Nerio LS, Verbel JO, Stashenko E. 2010. Repellent activity of essential oils: a review. Bioresour Technol 101: 372-378.

Perricone M, Arace E, Corbo MR, Sinigaglia M, Bevilacqua A. 2015. Review article bioactivity of essential oils: a review on the interaction with food components. Front Microbiol 6: 1-7.

Phasomkusolsil S, Soonwera M. 2010. Insect repellent activity of medicinal plant oils against Aedes aegypti (Linn.), Anopheles minimus (Theobald) and Culex quinquefasciatus Say based on 53.protection mean biting rate. Southeast Asian J Trop Med Public Health 41: 83140 .

Priyadarsini SS, Kumar PR, Thirumal M. 2018. Formulation and evaluation of a herbal antibacterial cream from ethyl acetate extract of leaves of Spinacia oleracea Linn. against Aeromonas skin and soft tissue infections. Intl J Green Pharm 12: S537-S542.

Ranasinghe MSN, Arambewela L, Samarasinghe S. 2016. Development of herbal mosquito repellent formulations. Intl J Pharm Sci Res 7: 3643-3648.

Shivhare RS, Kamble MA, Mahapatra DK et al. 2018. Development of mosquito repellant gel formulations from various natural volatile oils: comparative study with the marketed formulation Odomos®. J Drug Deliv Therapeut 8: 106-110.

Solomon B, Mariam TG, Asres K. 2012. Mosquito repellent actions of the essential oils of Cymbopogon citratus, Cymbopogon nardus, and Eucalyptus citriodora: evaluation and formulation studies. J Essential Oil Bearing Plants 15: 766-773.

Soonwera M. 2015. Efficacy of essential oils from citrus plants against mosquito vectors Aedes aegypti (Linn.) and Culex quinquefasciatus (Say). Intl J Agric Technol 11: 669-681.

Sritabutra D, Soonwera M. 2013. Repellent activity of herbal essential oils against Aedes aegypti (Linn.) and Culex quinquefasciatus (Say.). Asian Pac J Trop Dis 3: 271-276.

Standard Nasional Indonesia (SNI) 06-9353-1995. Minyak sereh. [Indonesian]

Standard Nasional Indonesia (SNI) 16-4399-1996. Sediaan tabir surya. [Indonesian]

Wany A, Kumar A, Nallapeta S, Jha S, Nigam VK, Pandey DM. 2014. Extraction and characterization of essential oil components based on geraniol and citronellol from Java citronella (Cymbopogon winterianus Jowitt). Plant Growth Regul 73: 133-145.

Wathoni N, Sriwidodo, Sofian FF, Narsa AC, Mutiara AN. 2018. Repellent activity of essential oils from Cananga odorata Lamk. and Cymbopogon nardus L. on corn starch-based thixogel. J Young Pharm 10 (2): s118-s123.

Weng DCJ, Latip J, Hasbullah SA, Sastrohamidjojo H. 2015. Optimal extraction and evaluation on the oil content of citronella oil extracted from Cymbopogon nardus. Malaysian J Anal Sci 19: 71-76.

Widawati M, Riandi U. 2015. Preliminary study of herbal topical lotion repellent made of betel leaves (Piper betle) and patchouli oil (Pogostemon cablin) mixture against yellow fever mosquito (Aedes aegypti). Biotropia 22: 45-51.

Yadav NP, Rai VK, Mishra N, et al. 2014. A Novel approach for development and characterization of effective mosquito repellent cream formulation containing citronella oil. BioMed Res Intl 2014: 786084. DOI: $10.1155 / 2014 / 786084$.

Zhu Q, Pan Y, Jia X, Li J, Zhang M, Yin L. 2019. Review on the stability mechanism and application of water-in-oil emulsions encapsulating various additives. Compr Rev Food Sci Food Saf 18: 1660-1675. 